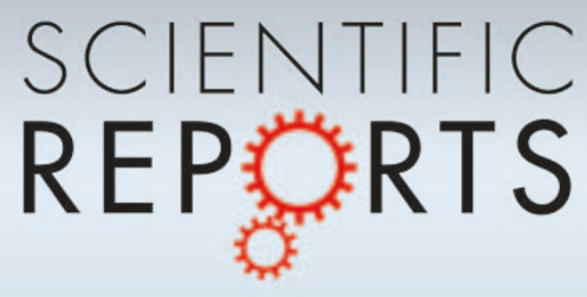

OPEN

SUBJECT AREAS:

CLIMATE CHANGE

BIODIVERSITY

OCEANOGRAPHY

COMPUTATIONAL BIOLOGY

Received

9 September 2011

Accepted

20 January 2012

Published

16 February 2012

Correspondence and requests for materials should be addressed to

M.H. (hashizum@ nagasaki-u.ac.jp) or N.M. (minakawa@ nagasaki-u.ac.jp)

\section{Indian Ocean Dipole drives malaria resurgence in East African highlands}

\author{
Masahiro Hashizume' ${ }^{1}$ Luis Fernando Chaves ${ }^{2} \&$ Noboru Minakawa'
}

\begin{abstract}
${ }^{1}$ Institute of Tropical Medicine (NEKKEN) and the Global Center of Excellence program on Tropical and Emerging Infectious Diseases, Nagasaki University, Nagasaki, Japan, ${ }^{2}$ Graduate School of Environmental Sciences and Global Center of Excellence program on Integrated Field Environmental Science, Hokkaido University, Sapporo, Japan.
\end{abstract}

Malaria resurgence in African highlands in the 1990s has raised questions about the underlying drivers of the increase in disease incidence including the role of El-Niño-Southern Oscillation (ENSO). However, climatic anomalies other than the ENSO are clearly associated with malaria outbreaks in the highlands. Here we show that the Indian Ocean Dipole (IOD), a coupled ocean-atmosphere interaction in the Indian Ocean, affected highland malaria re-emergence. Using cross-wavelet coherence analysis, we found four-year long coherent cycles between the malaria time series and the dipole mode index (DMI) in the 1990s in three highland localities. Conversely, we found a less pronounced coherence between malaria and DMI in lowland localities. The highland/lowland contrast can be explained by the effects of mesoscale systems generated by Lake Victoria on its climate basin. Our results support the need to consider IOD as a driving force in the resurgence of malaria in the East African highlands.

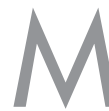
alaria resurgence in the East African highlands in the 1990s caused serious mortality and morbidity ${ }^{1,2}$. Although climate change in general and the El-Niño-Southern Oscillation (ENSO) in particular were strongly suspected to be related to epidemics in several highland regions in early $1998^{3,4}$, other large scale climatic factors are clearly associated with malaria risk in the highlands, because epidemics also occur during weak ENSO events. The Indian Ocean Dipole (IOD) causes above normal rainfall in East Africa during positive IOD events $s^{5,6}$. The availability of mosquito breeding grounds and vector populations both increase with rainfall ${ }^{7}$. A short-term temporal association between IOD and malaria incidence in the western Kenyan highlands has been reported ${ }^{8}$. However, it is still not clear if elements of the local climate relevant for malaria transmission, specially rainfall ${ }^{9}$ and malaria itself, have non-stationary signatures of the IOD on their dynamics over different time scales. This is of special interest provided the plausibility of regime shifts in climate caused by changes in the $\mathrm{IOD}^{10}$.

East African highland environments can be expected to be more sensitive to climatic variability because they are farther away from water basins such as lakes, and proximity to large water bodies generally stabilizes the climate. However, whether the pattern of exacerbated malaria transmission observed in the Western Kenyan highlands and associated with the IOD, is also found in adjacent lowland populations in the Lake Victoria basin remains an open question. Although it has been argued that the low immunity of highland human populations can explain the increased size of the epidemics in the late $1990 \mathrm{~s}^{11}$, the sensitivity of parasites and vectors to climatic variability can also affect the ecology of malaria transmission and more stable environments are less prone to epidemics ${ }^{12}$. Here we examine the hypotheses that 1) the re-emergence of highland malaria in the 1990s is associated with IOD activity and 2) the increased sensitivity to climatic variability in highland malaria transmission is underpinned by differences in environmental stability related to proximity of the various regions to Lake Victoria.

\section{Results}

Time-series of malaria hospital admissions show that epidemics began in the early 1990s and peaked in the mid to late 90s in the highlands (Kericho, Kisii and Kapsabet), while epidemics began in early the 1980s and peaked in the mid 80s in the lowlands (Maseno and Kendu Bay) (Figure 1). In general, the association with dipole mode index (DMI) is stronger and wider for all the studied time scales compared with Nino3, the ENSO index (Figure 2). Four-year long coherent cycles between malaria and DMI were seen in the 1990s data from the three hospitals in the highlands (Kisii, Kapsabet and Kericho). Coherence with DMI was less obvious in the lowlands (Maseno and Kendu Bay) while coherence with Nino3 was more obvious in Maseno and Kendu Bay in the data from the 198090s (4-16-year cycle). These patterns are supported by cross-correlation functions (Figure S1) and by autoregressive models that consider both DMI and Nino3 as forcing factors (Table S1). The best models for Kisii and 
A

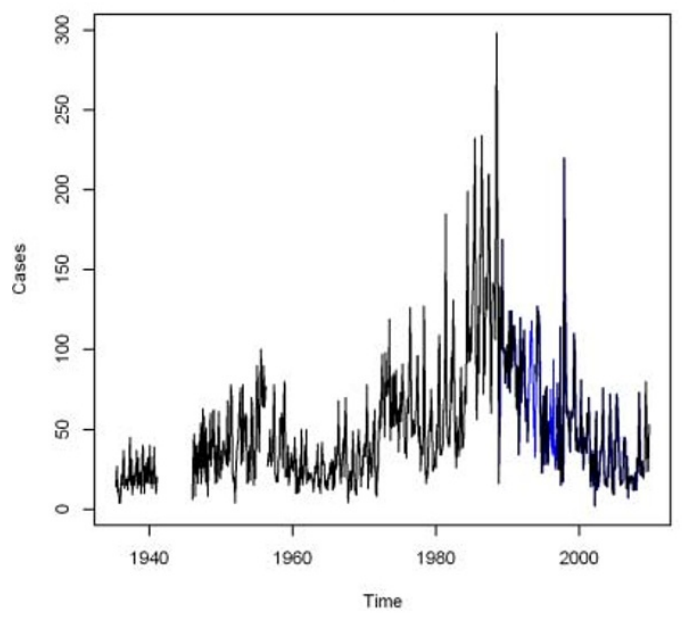

C

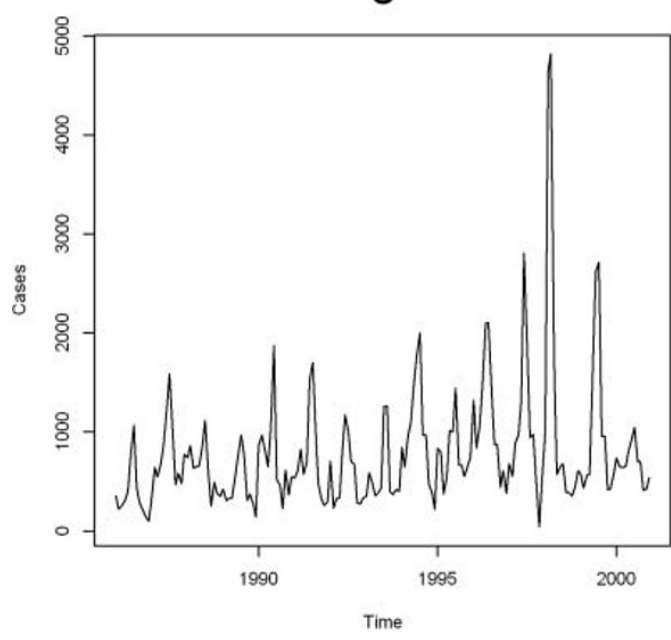

$\mathrm{E}$

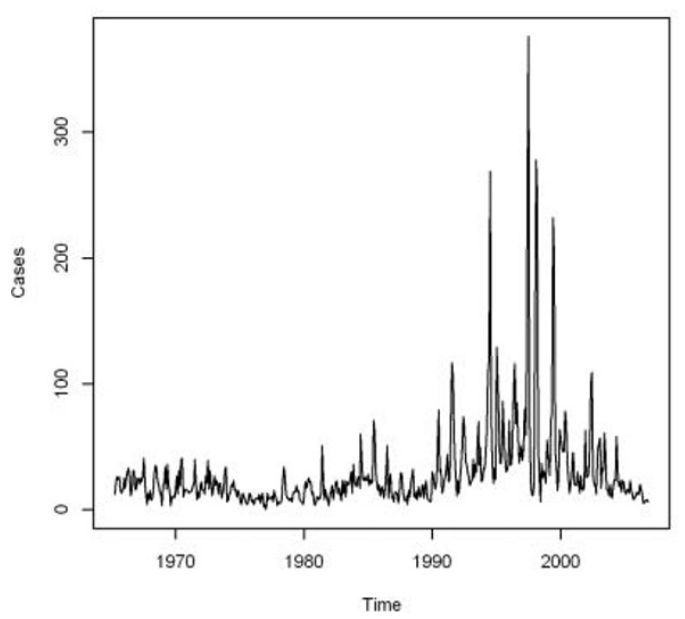

B
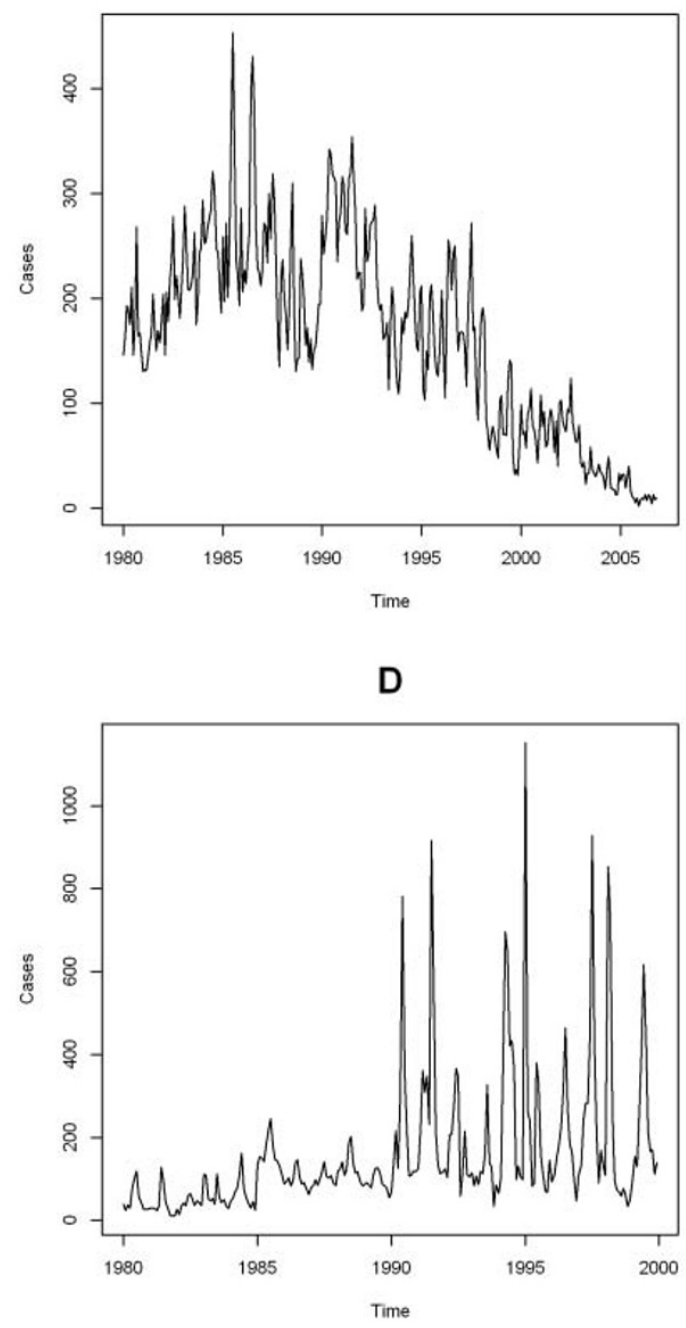

$\mathbf{F}$

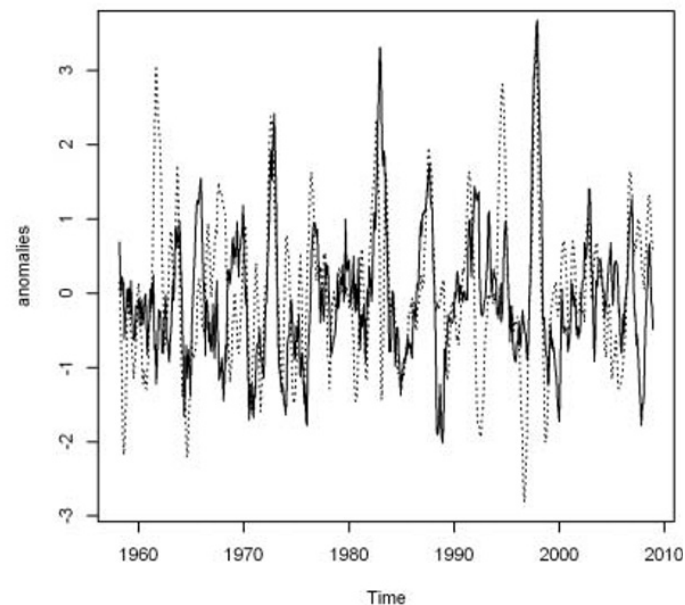

Figure 1 Malaria time series. Clinical records of malaria infections (A) Maseno (May 1935, November 2009, $0^{\circ} 00^{\prime} \mathrm{S}, 34^{\circ} 36^{\prime} \mathrm{E}$, Altitude $=1500 \mathrm{~m}$ ), blue indicates imputed values; (B) Kendu Bay (January 1980, November 2006, 0²4’ S, 34 39’ E, Altitude = 1240 m); (C) Kisii (January 1986, December 2000, $0^{\circ} 40^{\prime} \mathrm{S}, 34^{\circ} 46^{\prime} \mathrm{E}$, Altitude $\left.=1670 \mathrm{~m}\right)$; (D) Kapsabet (January 1980, December 1999, $0^{\circ} 12^{\prime} \mathrm{N}, 35^{\circ} 06^{\prime} \mathrm{E}$, Altitude $\left.=2000 \mathrm{~m}\right)$; (E) Kericho (April 1965, November $2006,0^{\circ} 23^{\prime} \mathrm{N}, 35^{\circ} 15^{\prime} \mathrm{E}$, Altitude = $2000 \mathrm{~m}$ ); (F) DMI, dipole mode index (dotted line) and Nino3, ENSO index (solid line, March 1958, December 2008). 
A
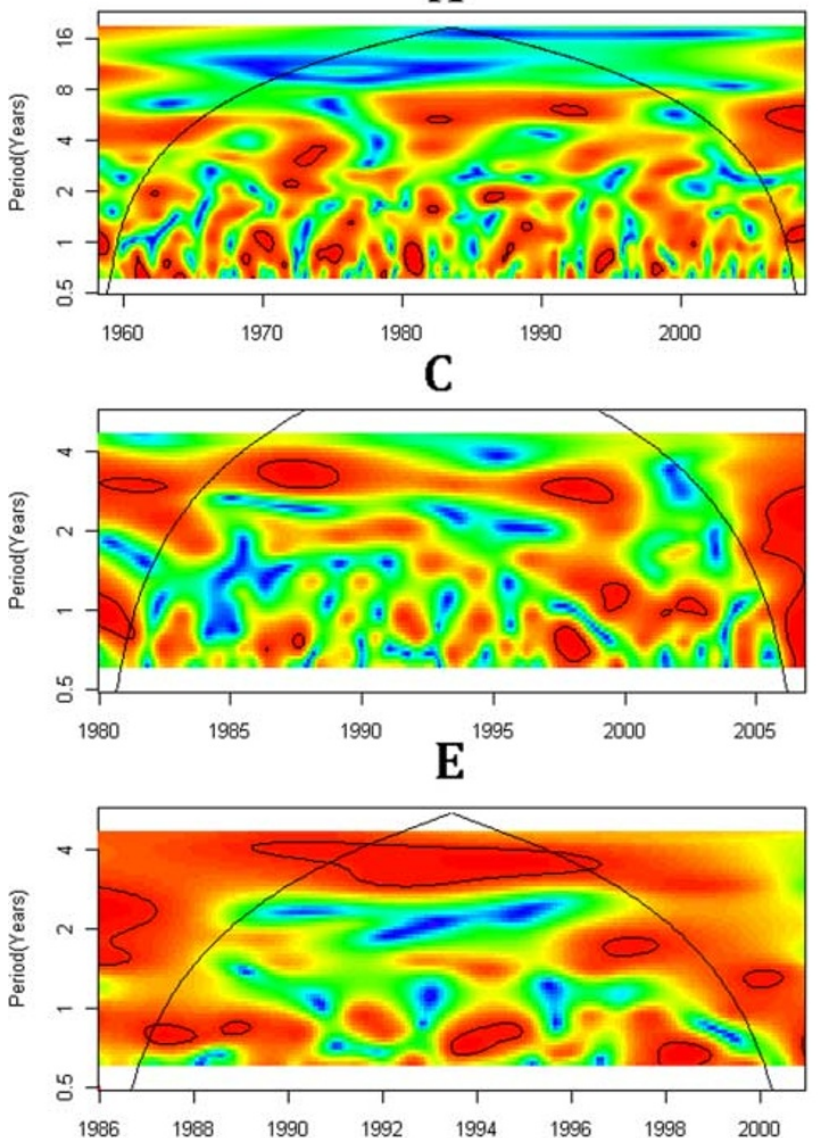

G
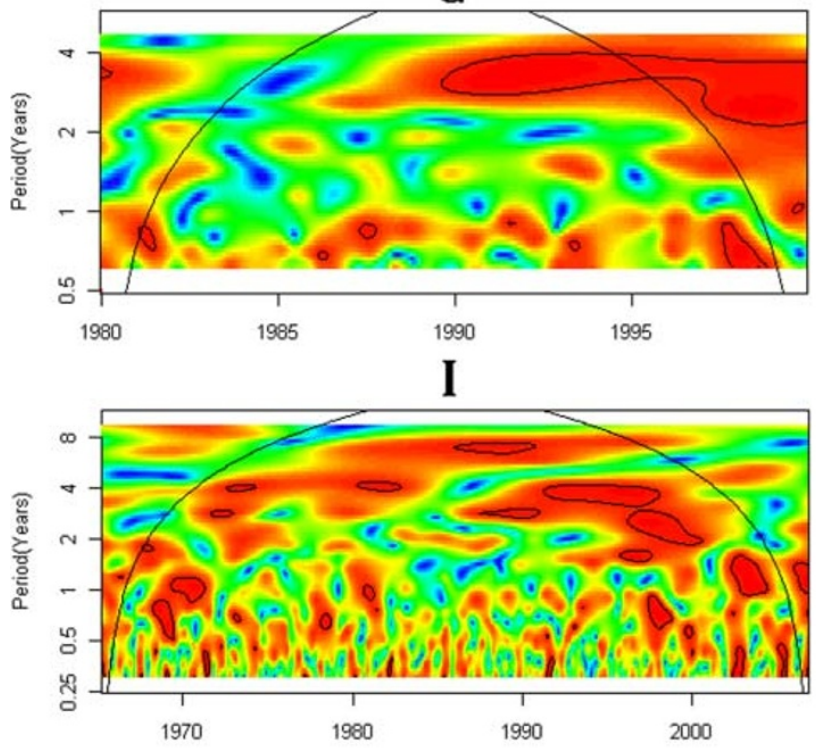

Time
B
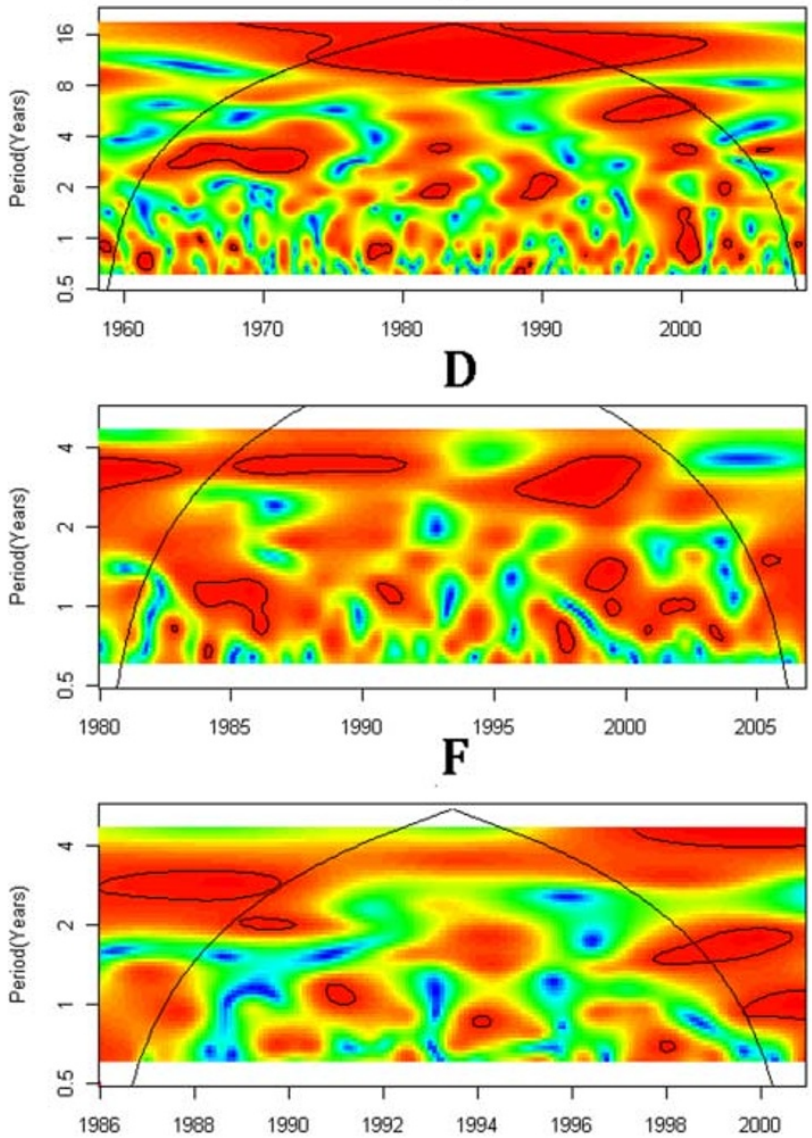

H

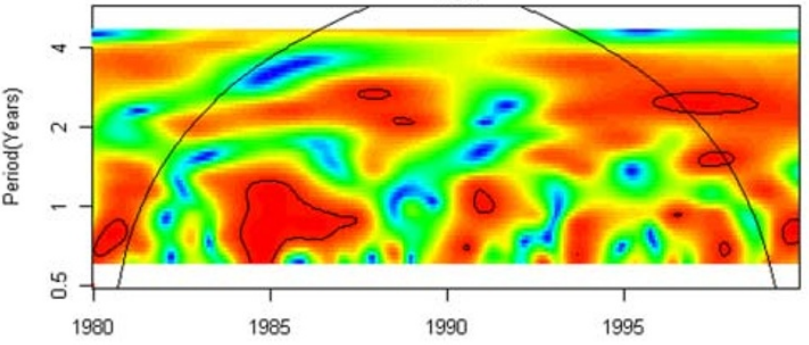

J

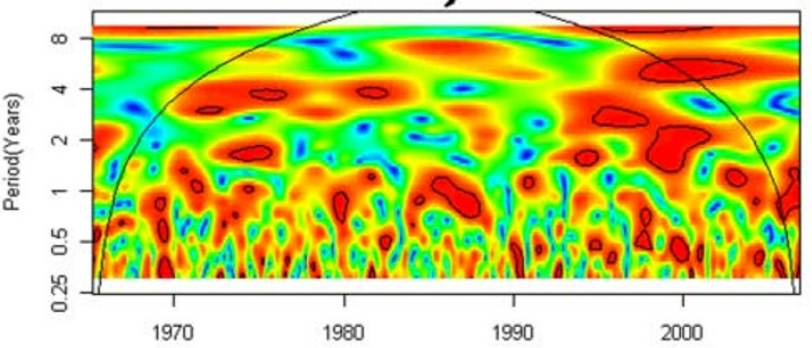

Time

Figure 2 Cross-wavelet coherence of the malaria time series with the DMI (dipole mode index) and with Nino3 (ENSO index). (A) Maseno and DMI (March, 1958, December 2008), (B) Maseno and Nino3 (March 1958, December 2008); (C) Kendu Bay and DMI; (D) Kendu Bay and Nino3; (E) Kisii and DMI; (F) Kisii and Nino3; (G) Kapsabet and DMI; (H) Kapsabet and Nino3; (I) Kericho and DMI; (J) Kericho and Nino3. The coherency scale is from zero (blue) to one (red). Red regions in the plots indicate frequencies and times for which the two series share variability. The cone of influence (within which results are not influenced by the edges of the data) and the significant coherent time-frequency regions $(\mathrm{p}<0.05)$ are indicated by solid lines. The procedures and software used are those described in Chaves and Pascual $(2006)^{30}$. A smoothing window of 6 months was used to compute the crosswavelet coherence. 
Kericho used a DMI with lags of 1 and 2 months, respectively, as a significant covariate. The local rainfall with a short-term lag (0 to 6 months) was a significant covariate in the best models for all 5 sites. During the model selection process, Nino3 was discarded as a significant covariate for all sites. A seasonal coherence between malaria and rainfall was observed in all 5 sites (Figure S2) and rainfall at all study sites (Figure S3) had a non-stationary relationship with both DMI and Nino3 (Figure S4).

\section{Discussion}

The finding that interannual cycles of the DMI coincide with malaria resurgence provides strong evidence that the IOD had an effect on the re-emergence of highland malaria in Western Kenya, probably through the impact of the DMI on rainfall. This association was less pronounced in adjacent lowlands closer to the Lake Victoria basin. Mesoscale systems generated by the lake have been shown to contribute significantly to climate variability over the lake basin ${ }^{13}$ while rainfall in the highlands was affected more by large-scale moisture from the equatorial Indian Ocean ${ }^{14}$. Rainfall in the highlands reduces dramatically as moisture from the equatorial Indian Ocean diminishes (Figure 3), indicating that highland weather is more sensitive to moisture from the equatorial Indian Ocean than from the Lake Victoria basin. The climate of the East African highlands is highly sensitive to perturbations during the short rainy season ${ }^{15}$ and the IOD may intensify and prolong the rainy season. Because the temperature of the highlands increases towards February, a prolonged short rainy season with warmer temperatures could enhance the development of mosquitoes and parasites ${ }^{16,17}$. As a result, the IOD may intensify the regional malaria transmission during the short rainy season. This synergy effect will be more profound in the highlands where temperatures are lower, and an increase in each of the factors (temperature and rainfall) is known to have an impact on mosquito populations ${ }^{16,18}$.

The results from autoregressive modelling also suggest that the effects of the IOD vary between the highland sites. Kapsabet is in the highlands (altitude $\approx 2000 \mathrm{~m}$ ) but its rainfall may be less affected by moisture from the equatorial Indian Ocean than the simulated rainfall in Kericho and Kisii. This is reinforced by the disappearance of the DMI in the best autoregressive model for Kapsabet (Table S1). Differences between the highland sites may be due to the complex topography of the regions that regulates the amount of moisture entering from the Indian Ocean.

The role of the ENSO in the interannual variability in East African rainfall has been extensively examined ${ }^{19,20}$. The results indicate that the ENSO has some influence on equatorial and coastal East African rainfall, with warm events being associated with higher rainfall and cold events with lower rainfall. However, the influence of the ENSO has decreased over the western Indian Ocean in recent decades, and the influence of the IOD on East African climates has increased ${ }^{10}$. Recent studies indicate that patterns of association between the IOD and rainfall are stronger, more regular and homogenous across East Africa $^{21,22}$. An atmospheric circulation model suggested that Indian Ocean sea surface temperatures (SSTs) exert a greater influence than Pacific SSTs over East African rainfall ${ }^{23}$. Similarly, our model showed that the DMI had a stronger association with rainfall than Nino3 in the highland areas we studied.

Although climatic phenomena are important drivers of malaria dynamics in the East African highlands, the IOD is not the only influence on the cycles of malaria incidence and non-climatic factors have also been implicated. Local enforcement of control measures potentially influences the seasonal and long-term variability of the incidence of malaria ${ }^{12}$. Chloroquine was effective in the suppression of malaria epidemics until the emergence of resistance ${ }^{24,25}$. Increased trends in human mobility between the highlands and endemic areas may also affect population vulnerability thereby modifying the magnitude of local relationships. Although these factors can modulate the reported associations with climatic factors, they are unlikely to vary in the same seasonal and interannual patterns as malaria. It therefore seems unlikely that these factors could produce the coherence identified in this study. However, the strength of the association may be greater or lesser according to such local conditions.

The devastating epidemics had largely abated by early 2000 s and in more recent years malaria appears diminishing in the east African highlands ${ }^{26}$. This may be the result of extensive distribution of insecticide treated bed nets and the use of artemisinin-based combination therapies as the first-line drug ${ }^{27-29}$. Further work to clarify the effect of IOD and other climate factors in more recent years would be of interest.

Our results help in part to resolve the inconsistent associations reported between ENSO and malaria epidemics, and indicate that they merely reflect the association between the IOD and the ENSO. We propose that the IOD should be considered as the more appropriate index to decipher the signature of climate changes in the resurgence of malaria in the African highlands in the 1990s.

\section{Methods}

Data. The primary dataset for this study was the monthly number of patients with malaria who were admitted to three hospitals (Kapsabet, Kisii and Kericho) in the western Kenyan highlands and two hospitals (Maseno and Kendu Bay) in the lowland areas surrounding Lake Victoria. The primary diagnosis of malaria was made by physicians at each hospital. All cases diagnosed in Kericho were confirmed microscopically, but only some cases from the other hospitals were microscopically confirmed. With the exception of the Maseno site, missing data were imputed by averaging incidence values for the month before and the month after the missing value. For Maseno, the monthly number of malaria cases between January 1993 and December 1996 was estimated by averaging the monthly values for the year before and the year after the missing values. The strength of the IOD was measured by the DMI, defined as the difference in SST anomalies between the western $\left(10^{\circ} \mathrm{S}-10^{\circ} \mathrm{N}\right.$, $\left.50^{\circ}-70^{\circ} \mathrm{E}\right)$ and eastern $\left(10^{\circ} \mathrm{S}-0^{\circ}, 90^{\circ}-110^{\circ} \mathrm{E}\right)$ tropical Indian Ocean ${ }^{5}$. The DMI data were obtained from the Japan Agency for Marine-Earth Science and Technology (JAMSTEC) (www.jamstec.go.jp/frcgc/research/d1/iod/). The DMI values were calculated using the SST data from the HadISST dataset. The base period for calculating anomalies was 1958-2008. The obtained values were standardized to zero mean and unit standard deviation. The strength of the ENSO was measured by SST anomalies (Nino3) in the Pacific Ocean, using data from the NOAA Climate Prediction Center (www.cpc.ncep.noaa.gov). The base period for calculating the anomalies was 1971-2000.

Statistical analysis. Nonstationary patterns of association in the time-frequency domain. Patterns of association in nonstationary time series can be studied using continuous wavelet transforms. Specifically, we used cross-wavelet coherence analysis to determine if peaks at a particular frequency and time in the disease correspond to similar peaks in a covariate.

Time-domain time-series analysis. Based on their autocorrelation functions, we fitted autoregressive models to the time series and included non-linear trends obtained using a locally weighted smoothing (LOESS) model. The autoregressive coefficients of the best model for each site were used to pre-whiten the series of climatic covariates, thus ruling out the likelihood of a spurious correlation caused by a common cyclical structure on the time series. Pre-whitening is a process that rules out spurious correlations between two time series, by removing (filtering) any common structure between the two studied time series ${ }^{30}$. The residuals of the malaria time series models and the pre-whitened covariates were then used to estimate cross-correlation functions (CCF). Climatic covariates selected from the CCFs were included in models, with and without breakpoints for regime shifts. Finally, models were selected using the Akaike information criterion.

Exploratory analysis. To explore the dynamics of the time series we performed an exploratory time series analysis and examined the autocorrelation function of the malaria outpatient time series ${ }^{31}$. An inspection of the plotted data showed that all malaria time series $\left(y_{t}\right)$ were likely to be first order seasonal autoregressive processes. Thus, we fitted the following seasonal autoregressive null model to the time series data:

$$
y_{t}=\mu+\phi_{1}\left(y_{t-1}-\mu\right)+\phi_{12}\left(y_{t-12}-\mu\right)+\phi_{1} \phi_{12}\left(y_{t-13}-\mu\right)+\alpha \operatorname{Trend}+\varepsilon_{\mathrm{t}}
$$

For the highlands of Kisii and Kericho we had to use a second model because the time series for those sites were better described by a second order autoregressive process:

$$
y_{t}=\mu+\phi_{1}\left(y_{t-1}-\mu\right)+\phi_{2}\left(y_{t-2}-\mu\right)+\alpha \text { Trend }+\varepsilon_{\mathrm{t}}
$$

In both models, $\mu$ is the average value of the time series, trend is non-linear estimated using LOESS (the error was assumed to be independent and normally distributed), and $\varepsilon_{t} \sim N\left(0, \sigma^{2}\right)$. We used this model to pre-whiten the time series of the following climatic covariates: rainfall, Nino3, and the DMI. Residuals of the model presented in 

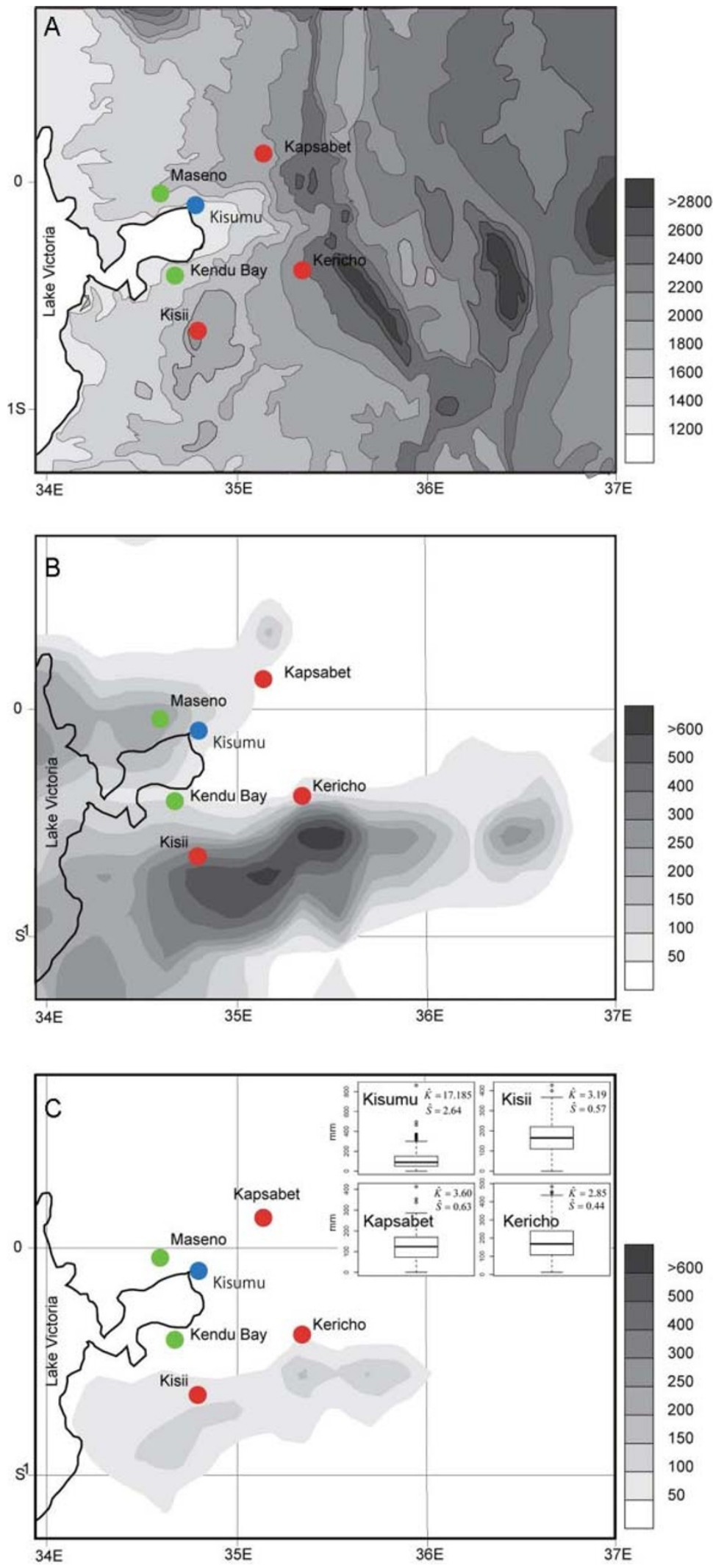

Figure 3 Elevation (m) (A) and simulated rainfall ( $\mathrm{mm}$ ) over the Lake Victoria basin with large-scale moisture through the eastern boundary reduced by (B) $20 \%$ and (C) 50\%. (Modified from Anyah et al. 2006 ${ }^{14}$ figure 10. ${ }^{\odot}$ American Meteorological Society. Reprinted with permission.) In all panels location color indicates the data available at each site; blue (rainfall); green (disease) and red (disease and rainfall). We used Kisumu rainfall data as a proxy for Kendu Bay and Maseno. Kisumu, like Kendu Bay and Maseno, is in the lowlands (A), with a similar rainfall regime (B and C). Panel C shows box plots for rainfall. Rainfall variability is measured by kurtosis $(\mathrm{K})$, and low values indicate a platykurtic distribution (one where conditions around the median are more variable). (S) indicates skewness. 
(1) and the pre-whitened residuals of the climatic covariates were used to compute cross-correlation functions for the number of outpatients with each one of the climatic covariates.

1. Lindsay, S. W. \& Martens, W. J. Malaria in the African highlands: past, present and future. Bull World Health Organ 76, 33-45 (1998).

2. Mouchet, J. et al. Evolution of malaria in Africa for the past 40 years: impact of climatic and human factors. J Am Mosq Control Assoc 14, 121-130 (1998).

3. Kilian, A. H., Langi, P., Talisuna, A. \& Kabagambe, G. Rainfall pattern, El Nino and malaria in Uganda. Trans R Soc Trop Med Hyg 93, 22-23 (1999).

4. Lindblade, K. A. et al. Highland malaria in Uganda: prospective analysis of an epidemic associated with El Nino. Trans R Soc Trop Med Hyg 93, 480-487 (1999).

5. Saji, N. H., Goswami, B. N., Vinayachandran, P. N. \& Yamagata, T. A dipole mode in the tropical Indian Ocean. Nature 401, 360-363 (1999).

6. Saji, N. H. \& Yamagata, T. Possible impacts of Indian Ocean Dipole mode events on global climate. Clim Res 25, 151-169 (2003).

7. Minakawa N, Sonye G. \& Yan G. Relationships between occurrence of Anopheles gambiae s.l. (Diptera: Culicidae) and size and stability of larval habitats. J Med Entomol 42, 295-300 (2005).

8. Hashizume, M., Terao, T. \& Minakawa, N. The Indian Ocean Dipole and malaria risk in the highlands of western Kenya. Proc Natl Acad Sci U S A 106, 1857-1862 (2009).

9. Pascual, M. et al. Shifting patterns: malaria dynamics and rainfall variability in an African highland. Proc R Soc B 275, 123-132 (2008).

10. Nakamura, N. et al. Mode shift in the Indian Ocean climate under global warming stress. Geophys Res Lett 36, L23708 (2009).

11. Alonso, D., Bouma, M. J. \& Pascual, M. Epidemic malaria and warmer temperatures in recent decades in an East African highland. Proc R Soc B 278, 1661-1669 (2011).

12. Chaves, L. F. \& Koenraadt, C. J. M. Climate change and highland malaria: fresh air for a hot debate. Q Rev Biol 85, 27-55 (2010).

13. Anyah, R. \& Semazzi, F. Simulation of the sensitivity of Lake Victoria basin climate to lake surface temperatures. Theor Appl Climatol 79, 55-69 (2004).

14. Anyah, R., Semazzi, F. \& Xie, L. Simulated physical mechanisms associated with multi-scale climate variability over Lake Victoria Basin in East Africa. Mon Weather Rev 134, 3588-3609 (2006).

15. Sun L, Semazzi FHM, Giorgi F \& Ogallo LA. Application of the NCAR regional climate model to Eastern Africa. Part 1: Simulation of the short rains of 1988. J Geophys Res 104, 6529-6548 (1999).

16. Minakawa, N. et al. Malaria vector productivity in relation to the highland environment in Kenya. Am J Trop Med Hyg 75, 448-453 (2006).

17. Ye, Y., Louis, V. R., Simboro, S. \& Sauerborn, R. Effect of meteorological factors on clinical malaria risk among children: an assessment using village-based meteorological stations and community-based parasitological survey. BMC Public Health 7, 101 (2007)

18. Koenraadt, C. J. et al. Low larval vector survival explains unstable malaria in the western Kenya highlands. Trop Med Int Health 11, 1195-1205 (2006).

19. Mutai, C. C. \& Ward, M. N. East African rainfall and the tropical circulation/convection on intraseasonal to interannual timescales. J Climate 13, 3915-3939 (2000).

20. Indeje M, Semazzi, F. H. M. \& Ogallo L. J. ENSO signals in East African rainfall seasons. Int J Climatol 20, 19-46 (2000).
21. Behera, S. K. et al. Paramount impact of the Indian Ocean Dipole on the East African short rains: A CGCM Study. J Climate 18, 4514-4530 (2005).

22. Black, E. The relationship between Indian Ocean sea-surface temperature and East African rainfall. Phil Trans R Soc A 363, 43-47 (2005).

23. Goddard, L. \& Graham, N. E. Importance of the Indian Ocean for simulating rainfall anomalies over eastern and southern Africa. J Geophys Res 104, 1909919116 (1999).

24. Shanks, G. D., Biomndo, K., Hay, S. I. \& Snow, R. W. Changing patterns of clinical malaria since 1965 among a tea estate population located in the Kenyan highlands. Trans R Soc Trop Med Hyg 94, 253-255 (2000).

25. Malakooti, M. A., Biomndo, K. \& Shanks, G. D. Reemergence of epidemic malaria in the highlands of western Kenya. Emerg Infect Dis 4, 671-676 (1998).

26. Chaves, L. F., Hashizume, M., Satake, A. \& Minakawa, N. Regime shifts and heterogeneous trends in malaria time series from Western Kenya Highlands. Parasitology 139, 14-25 (2012).

27. Ceesay, S. J. et al. Changes in malaria indices between 1999 and 2007 in The Gambia: a retrospective analysis. Lancet 372, 1545-1554 (2008).

28. O'Meara, W. P. et al. Effect of a fall in malaria transmission on morbidity and mortality in Kilifi, Kenya. Lancet 372, 1555-1562 (2008).

29. Zhou, G. et al. Changing patterns of malaria epidemiology between 2002 and 2010 in Western Kenya: the fall and rise of malaria. PLoS One 6, e20318 (2011).

30. Chaves, L. F. \& Pascual, M. Climate cycles and forecasts of cutaneous leishmaniasis, a nonstationary vector-borne disease. PLoS Med 3, e295 (2006).

31. Shumway, T. H. \& Stoffer, D. S. Time series analysis and its applications. (Springer, 2000)

\section{Acknowledgements}

We thank R. Snow for providing the hospital and meteorological data for Kericho. L.F.C. is funded by the Japan Society for the Promotion of Science. This study was supported in part by the Global COE Program, Nagasaki University, Japan and Nagasaki University Cooperative Research Grant.

\section{Author contributions}

M.H. and N.M. designed the study and collected the data. L.F.C. analyzed the data. M.H L.F.C. and N.M. drafted the manuscript. All authors discussed the results and contributed to the final manuscript.

\section{Additional information}

Supplementary information accompanies this paper at http://www.nature.com/ scientificreports

Competing financial interests The authors declare no competing financial interests. License: This work is licensed under a Creative Commons Attribution-NonCommercial-ShareAlike 3.0 Unported License. To view a copy of this license, visit http://creativecommons.org/licenses/by-nc-sa/3.0/

How to cite this article: Hashizume, M., Chaves, L.F. \& Minakawa, N. Indian Ocean Dipole drives malaria resurgence in East African highlands. Sci. Rep. 2, 269; DOI:10.1038/ srep00269 (2012). 